\title{
Cellulose Microfibril from Banana Peels as a Nanoreinforcing Fillers for Zein Films
}

\author{
Manisara Phiriyawirut ${ }^{*}$, Parichat Maniaw \\ Department of Tool and Materials Engineering, Faculty of Engineering, King Mongkut's University of \\ Technology Thonburi, Bangkok, Thailand \\ Email: ${ }^{*}$ manisara.pee@kmutt.ac.th
}

Received February 6, 2012; revised March 14, 2012; accepted March 25, 2012

\begin{abstract}
Cellulose microfibril (CMF) was the extraction with acid mixture from peel of Musa sapientum Linn type of banana (Kluai Nam Wa). The fibrous-shape of CMF interconnected weblike structure with the average diameter $26 \mathrm{~nm}$ were observed by TEM. In order to prepare zein/CMF nanocomposite films, $16 \mathrm{wt} \%$ zein solution was prepared by dissolved in $80 \%$ ethanol aqueous solution which contain glycerol $20 \% \mathrm{w} / \mathrm{w}$. The suspension of CMF and zein solution was mixed with $0 \%-5 \%$ weight fractions of solid CMF in zein matrix. The morphology of the zein films is more roughness by increased amount of cellulose microfibrils. It was found that as CMF content increase from 0 to $5 \mathrm{wt} \%$ results in increasing tensile strength and Young's modulus of zein nanocomposite films. The highest strength obtains at $4 \mathrm{wt} \%$ $\mathrm{CMF}$.
\end{abstract}

Keywords: Zein; Cellulose Microfibril; Nanocomposite; Reinforcement

\section{Introduction}

Natural fibers are subdivided based on their origins, coming from plants, animals or minerals. Especially, natural fibers which come from plant, they are also referred to as cellulosic fibers, related to the main chemical component cellulose, or as lignocellulosic fibers, since the fibers usually often also contain a natural polyphenolic polymer, lignin, in their structure. In recent years, the use of natural fibers as reinforcements in polymers and composites has attracted much attention due to the environmental concerns such as sisal [1], cotton [2], bamboo [3], jute [4], kenaf [5] and wood [6]. Compared to inorganic fillers, the main advantages of lignocellulosics are renewable nature, wide variety of fillers available throughhout the world, low energy consumption, low cost, low density, high specific strength and modulus (desirable fiber aspect ratio), high sound attenuation, and comparatively easy processability due to their flexibility and nonabrasive nature which allow high filling levels.

Nevertheless, despite these attractive properties, lignocellulosic fillers are used only to a limited extent in industrial practices, mainly due to difficulties associated with surface interactions. An alternative way to palliate this restriction consists of obtaining both components (matrix and filler) dispersed in water such as colloidal suspensions of cellulose whiskers. In addition, cellulose

*Corresponding author. can also be used as a microfibrillar filler, which is more accessible in terms of available amounts and preparation. Cellulose microfibrils (CMF) can be found as intertwined microfibrils in the parenchyma cell wall, in particular from plant.

Cellulose whiskers have generated a great deal of interest as a source of nanometer size filler because of very good mechanical properties [7]. The microfibril diameters range from 2 to $20 \mathrm{~nm}$ and their lengths can reach several tens of microns depending on their origin, thus they have a very high aspect ratio and a significant load-carrying capability. Another type of cellulose, CMF is a diameter range of $10-100 \mathrm{~nm}$, but with a web-like structure [8]. Cellulose nanowhiskers and CMF have been isolated from various sources such as sugar beet [9], potato pulps [10], algae [11], cactuses [12], banana rachis [13] and banana peel [14].

The use of cellulose nanowhiskers and CMF in composite materials has been reviewed [7]. Both natural and synthetic polymers have been used as matrices including starch [15], chitosan [16], poly(vinyl chloride) [17], and natural rubber [14], etc. Most of the composites have shown a significant improvement in properties.

In this work, CMF which is prepared from peel of Musa sapientum Linn type of banana (Kluai Nam Wa) was used as reinforcement filler of zein films which prepared by solution casting technique. The effect of CMF content on morphology, chemical structure, crystal struc- 
ture, thermal and mechanical properties of composite films were investigated and reported here.

\section{Experimental}

\subsection{Materials}

CMF was prepared according to Organosolv treatment [13]. Briefly, dry powder size of $300 \mu \mathrm{m}$ from banana peel were alkaline extracted, bleached with hydrogen peroxide and hydrolysed by mixing of nitric acid and acetic acid.

Zein powder from maize with molecular weight of 25,000 - 29,000 was obtained from Fluka. Ethanol (reagent grade, J. T. Baker) and glycerol (Ajax Finechem) were used as-received.

\subsection{Nanocomposite Films Preparation}

In order to prepared zein/CMF nanocomposite films, zein solution with $16 \%$ wt was prepared by dissolved in $80 \%$ ethanol aqueous solution which contain glycerol $20 \%$ $\mathrm{w} / \mathrm{w}$. The suspension of CMF and zein solution were mixed with $0 \%-5 \%$ weight fractions of solid CMF in zein matrix. After well mixing of CMF and zein solution, the nanocomposite zein films were casted in a plastic mold and dried at $50^{\circ} \mathrm{C}$ for $4 \mathrm{hr}$.

All sample specimens were kept at desecrator with $25^{\circ} \mathrm{C}, 50 \% \mathrm{RH}$ for at least $48 \mathrm{hr}$ before testing to ensure the stabilization of their moisture content.

\subsection{Nanocomposite Film Characterization}

Infrared spectra of the as-prepared nanocomposite films were recorded by Perkin-Elmer FTS175 spectrophotometer (FTIR).

TEM morphology of as-prepared CMF was examined by JEOL JEM-1230 while, SEM morphology of as-prepared nanocomposite films were examined JEOL JSM6380LV operating at $1.5 \mathrm{kV}$. Prior observation under SEM, the nanocomposite films were coated with a thin layer of gold.

$X$-ray diffractometer (XRD) was used for study the crystal structure of the nanocomposite films. XRD patterns were obtained by Bruker axx D8DISCOVER. The $X$-ray source was $\mathrm{Cu} \mathrm{K} \alpha$. The measurements covered the scanning range of $10-50$ at a scanning speed of $0.05 \mathrm{~s}^{-1}$.

A Mettler Toledo DSC822e (DSC) was used for investigated thermal behavior of the films. To set the thermal history for all samples, each sample was first heated to $200^{\circ} \mathrm{C}$ and then cooled to $0^{\circ} \mathrm{C}$ at the scanning rate of $10^{\circ} \mathrm{C} \times \mathrm{min}^{-1}$. The thermal properties of the films were measured in the second heating scan at the heating rate of $10^{\circ} \mathrm{C} \times \min ^{-1}$. The glass transition temperature $\left(T_{g}\right)$ and the melting temperature $\left(T_{m}\right)$ were determined as the inflection point of the specific heat increment and the onset of the endothermic melting peak of DSC traces, respec- tively.

Mechanical properties in term of tensile strength, elongation at break and Young's modulus were investigated. These measurements were carried out using a Texture analyzer Stable Micro System TA. XT plus, with the maximum load of $10 \mathrm{kN}$. A crosshead speed of $10 \mathrm{~mm} /$ min and gauge length of $50 \mathrm{~mm}$ were used.

\section{Results and Discussion}

\subsection{Morphology}

The product of Organosolv treatment from banana peel is presented in the form of colloidal CMF suspension in water media. TEM morphology of CMF was shown in Figure 1. It was found the CMF was fibrous-shaped, long and web-link structure with average diameter of 26 $\mathrm{nm}$.

In manufacturing of protein-based films require plasticization of the protein in order to improve the flexibility of films and make them easy to handle. Then glycerol was added into the zein solution in order to improve zein films flexibility. Figure 2 shows the SEM micrograph of zein films with and without $20 \%$ glycerol content. It was found that surface morphology of pure zein film was smooth but fine pores were observed for zein film with $20 \%$ glycerol.

The plasticization of a polymer is a complex step-bystep phenomenon, comprising 1) wetting and adsorption; 2) solvation and/or penetration of the surface; 3) absorption, diffusion; 4) dissolution in the amorphous regions; and 5) structure breakdown [18]. Then, the morphology change of zein film, observation of fine pores in the pre-sented of glycerol was disruption or changing of intermolecular reaction between zein and glycerol [19].

SEM micrographs of zein/glycerol composite films with CMF content of 0 - 5 wt $\%$ were showed in Figure 2.

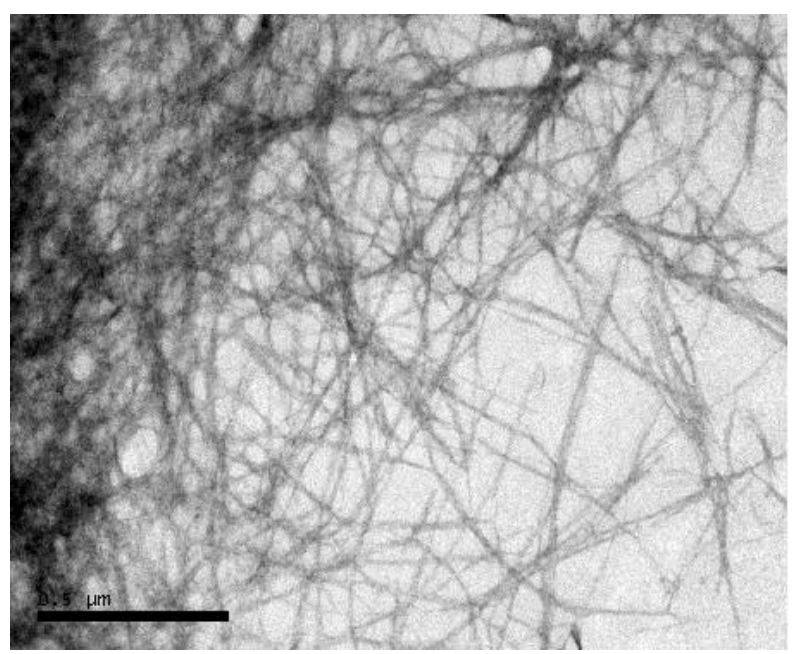

Figure 1. TEM micrograph of as-prepared CMF. 

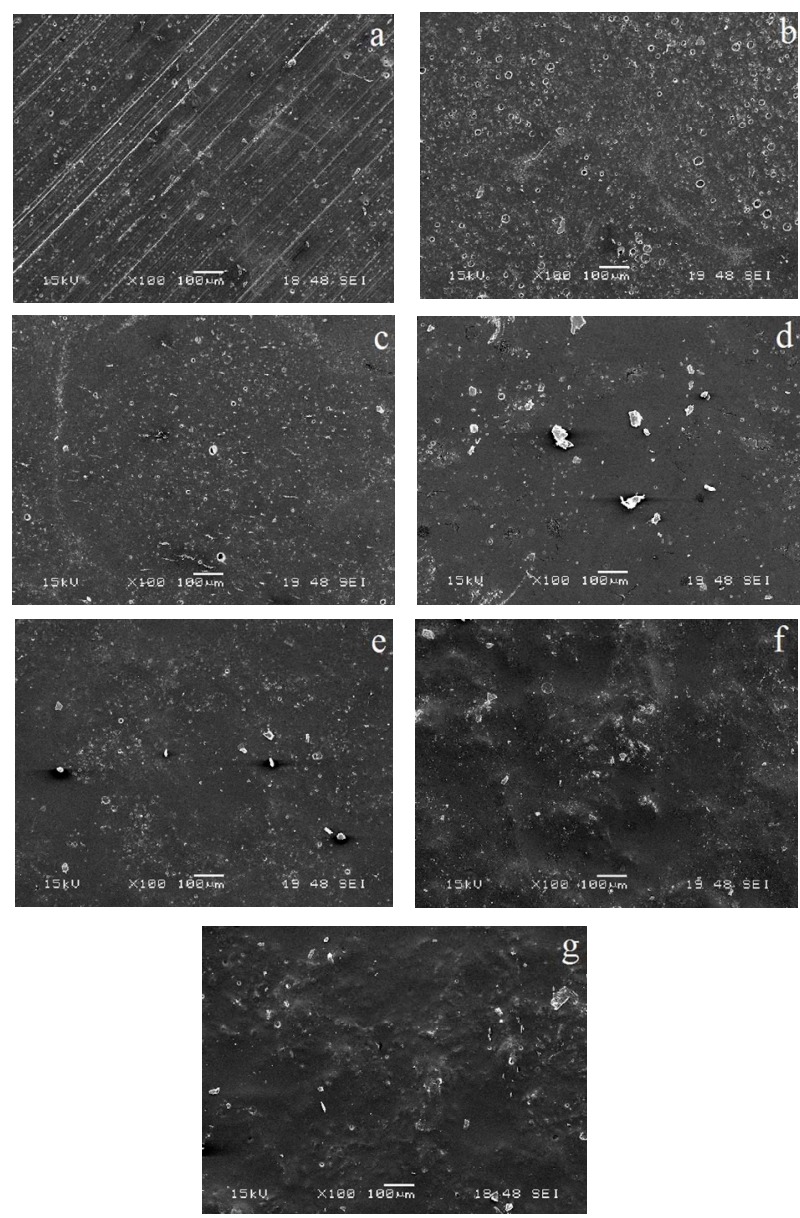

Figure 2. SEM micrographs of the surface of zein films having the glycerol content of (a) $0 \%$; and (b) $20 \%$, respectively and zein/CMF nanocomposite films having the CMF content of (c) $1 \%$; (d) $2 \%$; (e) $3 \%$; (f) $4 \%$; and (g) $5 \%$, respectively.

It was found that small white dots were observed and became more clearly with $3 \%$ of CMF content. Higher content of $\mathrm{CMF}$, agglomeration of $\mathrm{CMF}$ was occurred and it is the reason of roughly surface of zein films. In addition, numbers of the fine pore on the surface of the film were decreased by increasing of CMF content. The reduction in the number of fine pore could be a result of interaction between CMF molecules and zein.

\subsection{Chemical Characteristics}

Zein/CMF nanocomposite films in various CMF content were prepared using ethanol solution as the common solvent, respectively. To investigate the chemical characteristics of the films, FT-IR was employed. Figure 3 shows FT-IR spectra of pure CMF film (i.e. the topmost curve), and a series of zein/CMF nanocomposite films in various $\mathrm{CMF}$ content.

It is apparent from Figure 3 that as-prepared CMF FTIR pattern shows the characteristic hydroxyl-stretching

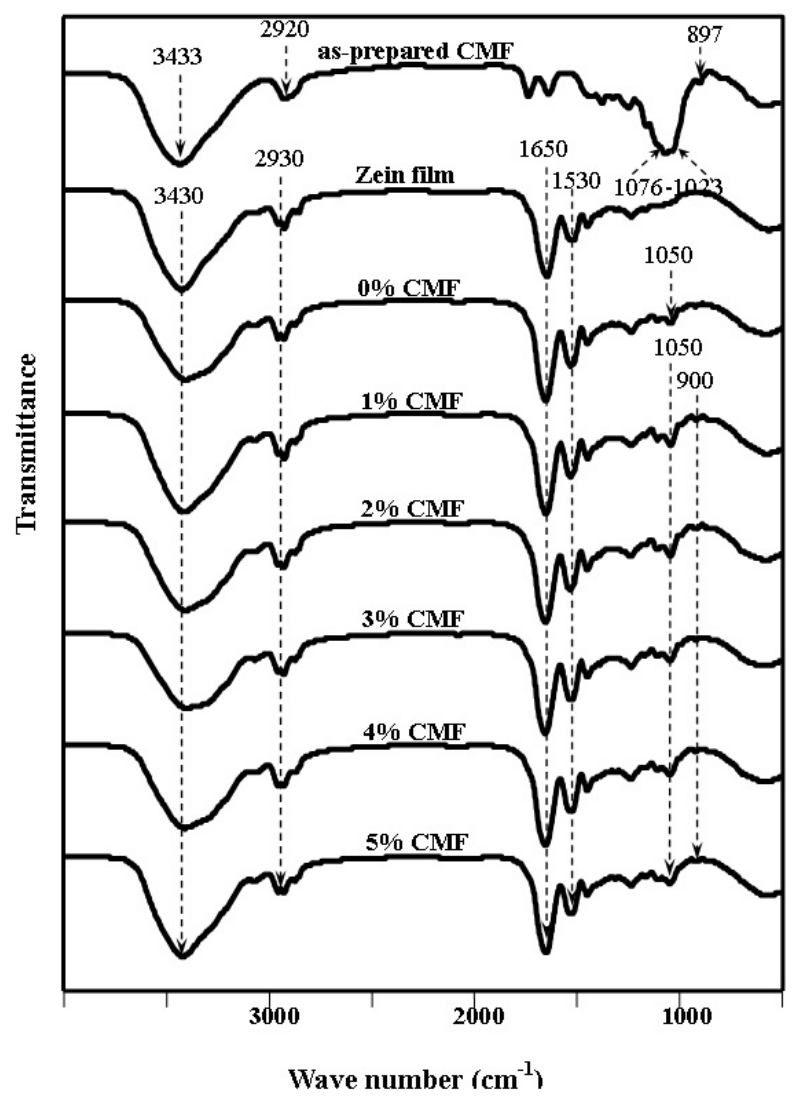

Figure 3. FT-IR spectra of as-prepared CMF, and zein/ CMF nanocomposite films.

absorption peak at $3433 \mathrm{~cm}^{-1}$, CH stretching absorption peak at $2920 \mathrm{~cm}^{-1}$, and characteristic absorption peak of glucopyranose unit of hemi-cellulose and $\beta$-glycosidic linkage between glucose units of cellulose at 1023 - 1017 $\mathrm{cm}^{-1}$ and $897 \mathrm{~cm}^{-1}$, respectively. The characteristic peaks of zein were appeared at $3430 \mathrm{~cm}^{-1}$ (OH stretching), $2930 \mathrm{~cm}^{-1}$ (CH stretching) and $1650 \mathrm{~cm}^{-1}$ (Amide I and $\mathrm{N}-\mathrm{H}$ bending), $1530 \mathrm{~cm}^{-1}$ (Amide II) which two last groups were related to the type of amino acid in protein molecule [20]. Since the glycerol was added in order to improve the flexibility of zein film, it was found that no significantly shift in characteristic peaks of zein but it was found the appearance of absorption peak at 1050 $\mathrm{cm}^{-1}$ (OH bending) of glycerol.

For the zein/CMF nanocomposite films, the FT-IR spectra were found the same characteristic peak as appeared in zein film containing glycerol but the intensity and the broad of these peaks (3430, 2930, 1650 and 1530 $\mathrm{cm}^{-1}$ ) were more pronounce with increasing CMF content. This phenomenon gives absorption peaks at the same position of pyranose group of hemi-cellulose in $\mathrm{CMF}$. Moreover, it was also found the absorption peak at $900 \mathrm{~cm}^{-1}$ which refer the $\beta$-glycosidic linkage.

Since, apart from the absorption peaks specific to zein/glycerol and CMF is observed in all of the nano- 
composite films, no additional peaks signifying possible interaction between zein and CMF were observed. It is logical to postulate that the interaction between zein and CMF may existent but too weak to be detected by FT-IR.

\subsection{Crystal Morphology}

XRD provides evidence of the crystal morphology. Figure 4 illustrates XRD diffractogram for pure $\mathrm{CMF}$, and a series of zein/CMF nanocomposite films.

As shown in Figure 4, The diffractogram of CMF shows two peaks around $2 \theta=15.9^{\circ}$ with broad shape (peak 1) and $22^{\circ}$ with sharp shape (peak 2). This diffractogram was quite altered from the previous report [21] which gave cellulose diffractogram at $2 \theta=15.5^{\circ}$ (peak 1), $16.5^{\circ}$ (peak 2), and $22.6^{\circ}$ (peak 3). The $2 \theta$ s were correspond to $d$ values of 5.72, 5.37, and 3.93 angstrom, respectively, and these diffraction peaks are typical of cellulose $I$. Peak 1 is $I_{\alpha}(100)$ and $I_{\beta}(110)$; peak 2 is $I_{\alpha}$ $(010)$ and $I_{\beta}(110)$; and peak 3 is $I_{\alpha}(110)$ and $I_{\beta}(200)$.

The main peak in the XRD diffractogram of zein films with and without glycerol was appeared at the $2 \theta$ angle of ca. $18.5^{\circ}$. Since CMF were incorporated into the zein film, it was found no other peak appeared or shifted but the shape of peak at $2 \theta$ angle of ca. $18.5^{\circ}$ was became broader and shape-like cellulose crystalline peak when increasing $\mathrm{CMF}$ content. The incorporation of $\mathrm{CMF}$ seemed not to affect the crystallinity of the zein matrices since no relevant changes on their diffraction pattern were observed. This was probably due to the low amount of CMF in the film.

The result from this contribution paper was good agreed with $\mathrm{Lu}$ and coworker [22] who study the effect of microfibrillated cellulose on crystal morphology of PVS. It was found that, the diffractograms of the composite PVA films display the superposition of those of the two components. The intensity of the diffraction peaks

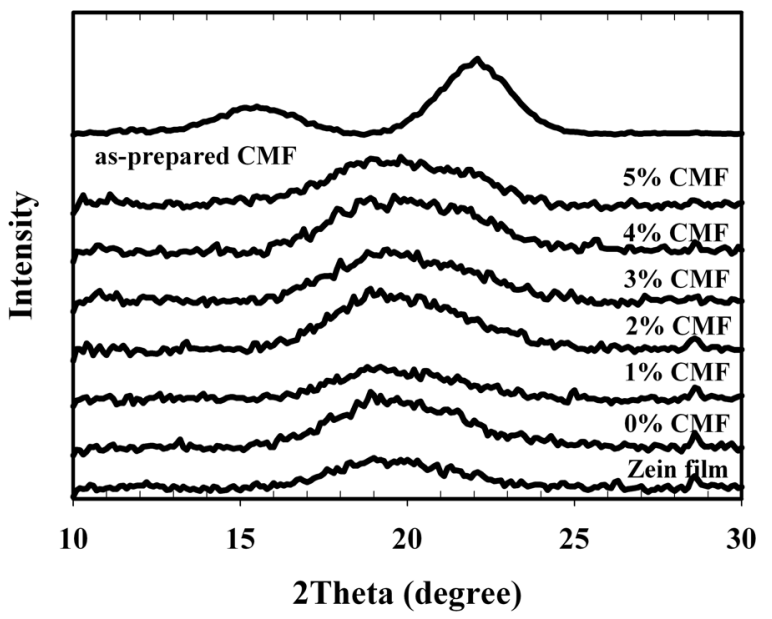

Figure 4. XRD pattern of as-prepared CMF and zein/CMF nanocomposite films. resulting from microfibrillated cellulose is directly proportional to the concentration of microfibrillated cellulose.

\subsection{Tensile Properties}

The reinforcement effect of CMF on the mechanical properties of zein/CFM nanocomposite films was evaluated up to their failure, as a function of the CMF content. The tensile strength at break, the percentage of elongation at break, and the Young's modulus of zein/CFM nanocomposite films were shown in Figure 5.

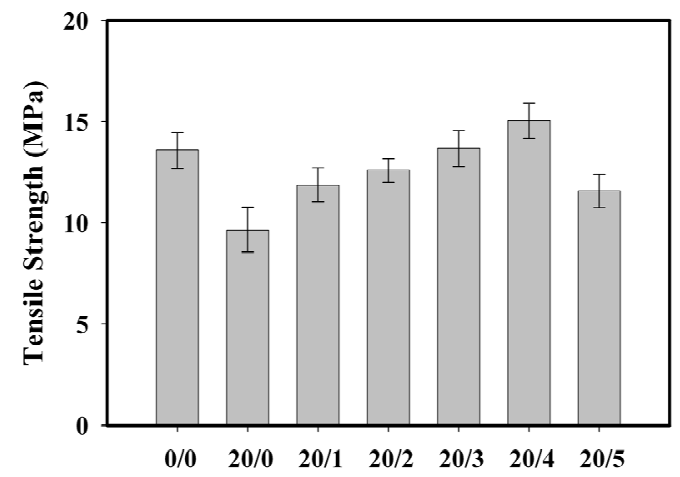

(a)

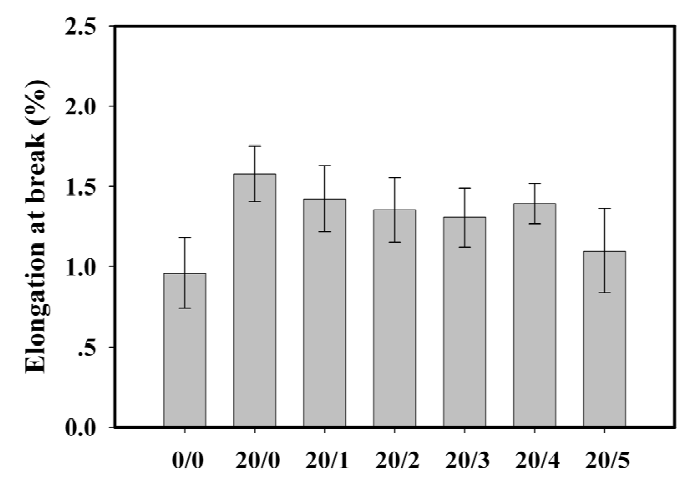

(b)

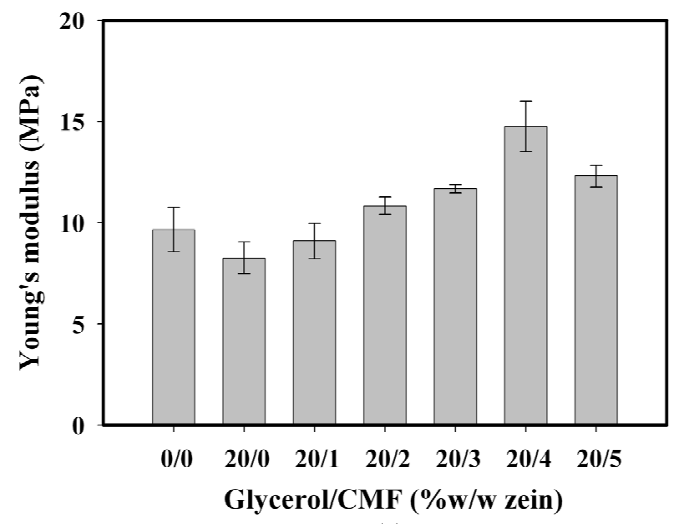

(c)

Figure 5. Tensile properties of zein/CMF nanocomposite films plotted as a function of glycerol/CMF ratio: (a) Tensile strength at break; (b) Percentage of elongation at break; and (c) Young's modulus. 
It was found that pure zein film was brittle with value of $13.58 \mathrm{MPa}, 9.97 \mathrm{MPa}$ and $0.96 \%$ for tensile strength, Young's modulus and percentage of elongation at break, respectively. In order to improve flexibility of zein film, glycerol was added and it has an improvement the percentage of elongation at break from 0.96 to 1.58 . However, glycerol molecules were affecting to the strength and modulus of the film as well. Generally addition of plasticizer such as glycerol or sorbitol is reducing the intramolecular force among polymer chains. It has been attributed to ease of polymer mobility, thus increase in the polymer flexibility. However, there are corresponding lowering the strength and modulus of the polymer chain. These results were similar to report of Parris and Coffin [23] which study the effect of polyethylene glycol on mechanical of zein. It was found that tensile strength of polyethylene glycol added zein film is decreased from 10.9 $\mathrm{MPa}$ to $5.7 \mathrm{MPa}$, while the elongation at break isincreased about by $2.8 \%$.

The reinforcement effect of CMF on mechanical properties of zein nanocomposite was clearly observed. It was found that as CMF content increase from 0 to $5 \mathrm{wt} \%$ results in increasing from 11.8 to $15.05 \mathrm{MPa}$ for tensile strength and from 9.11 to $14.75 \mathrm{MPa}$ for Young's modulus of zein nanocomposite films. The highest strength occurs at $4 \mathrm{wt} \% \mathrm{CMF}$.

With higher CMF content, aggregation of microfibril reduces both strength and modulus of the films. This result was agree with SEM which shown aggregation of $\mathrm{CMF}$ at $5 \mathrm{wt} \%$ loading in nanocomposite film. The aggregation of CMF is affected to the strength of zein film by alter the force transfer between zein molecule and CMF. Increasing of CMF content is also affect to slightly decrease the percentage of elongation at break of the composite films. There are two reasons to explain this phenomenon. The first one is higher CMF content caused higher rigidity of composite film. Another explanation is the composite film has higher interaction between cellulose and glycerol, via $\mathrm{OH}$ group. It causes lowering the plasticizing effect of glycerol on zein molecules, as a result, the percentage of elongation at break is decreased.

\subsection{Thermal Properties}

The DSC technique is one of the convenient methods for investigating the thermal properties of polymer blends and composites, therefore it was used for investigation the thermal properties of zein/CMF nanocomposite films on the glass transition $\left(T_{g}\right)$ and crystalline melting temperature $\left(T_{m}\right)$.

For CMF which is composted of both crystalline part and amorphous part, thus the $T_{g}$ could not be detected by DSC method. Sun and coworker [24] studied the method to isolation of cellulose from sugarcane bagasse and it was characterized. From the TGA and DSC experiment, it was found that isolated cellulose from nitric acid/acetic acid solution was degraded at $320^{\circ} \mathrm{C}$. Especially in DSC thermogram, exothermic peak centered at $340^{\circ} \mathrm{C}$ was appeared. This exothermic peak is the disintegration of intramolecular interaction and the decomposition of the polymer. However, the degradation study of CMF in this paper was not focus.

Figure 6 shows the DSC thermograms for zein/CMF nanocomposite films. The numbers assigned in the figure are $T_{g}$ of the nanocomposite films. The thermal transition point of zein is the middle point of endothermic peak at $87^{\circ} \mathrm{C}$. This point is correlated to the energy for hydrogen bonding dissociation which related to increasing of protein mobility, thus we postulate that it should be the $T_{g}$ of zein [25].

There are no baseline shift in the DSC thermogram of biopolymer, the $T_{g}$ was assumed by the onset, middle or end point of the endothermic peak. As seen in Figure 6, pure zein film gives peak at ca. $81^{\circ} \mathrm{C}$ but it will be shifted to lower temperature at ca $69.5^{\circ} \mathrm{C}$ when zein incorporated with glycerol. The lowering of the $T_{g}$ value of zein by adding glycerol is the plasticizing effect of glycerol

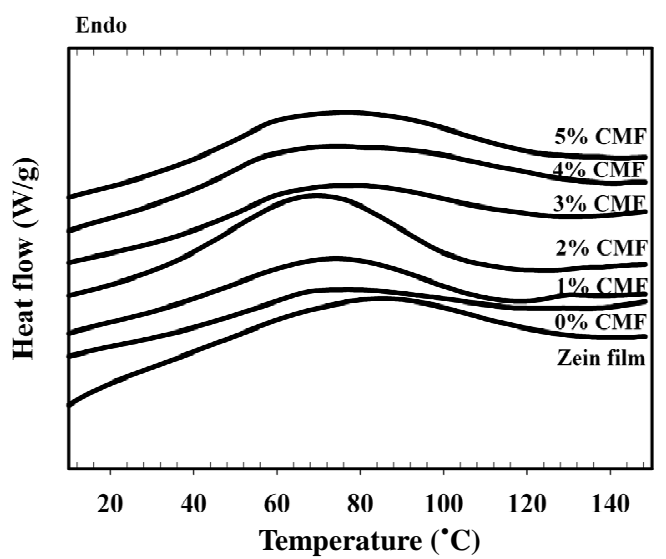

(a)

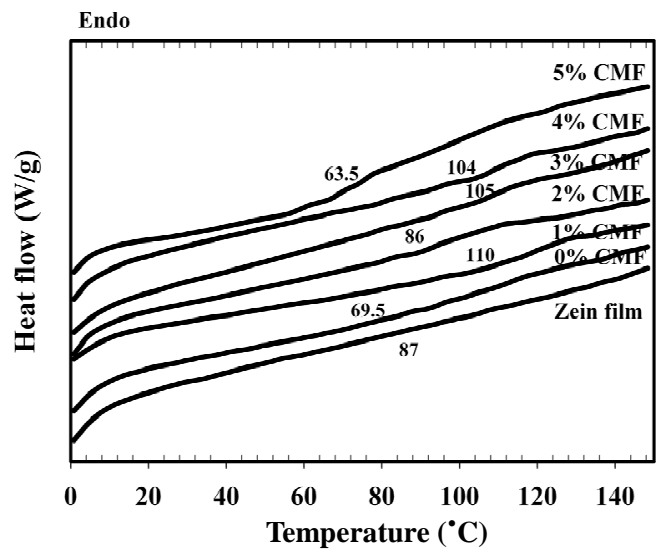

(b)

Figure 6. DSC thermograms of zein film and zein/CMF nanocomposite films with (a) 1st heating scan; and (b) 2nd heating scan. 
which improves the polymer chain mobility. As Ghanbarzadeh and cowork [26] reported that water is the main plasticizer of biopolymer such starch and gluen and result in lowering their $T_{g}$. The $T_{g}$ value of anhydrous, high molecular weight starch is $200^{\circ} \mathrm{C}$ but change to $-10^{\circ} \mathrm{C}$ for hydrated starch. This result is in good agreement to Magoshi and coworker [27] which studying the $T_{g}$ of zein at different moisture content. It was found that the $T_{g}$ value of zein is decreased from $139^{\circ} \mathrm{C}$ to $47^{\circ} \mathrm{C}$ when increasing moisture content from $0 \%$ to $6.6 \%$.

Baseline of DSC thermogram in CMF reinforced zein film is shift to higher temperature as indication of increasing $T_{g}$ value as increasing of CMF content (Figure 6(b)). This slightly increase in $T_{g}$ value is probably due to higher restriction chain mobility resulting from the presence of CMF between zein molecules. This result is in good agreement to mechanical properties results which gives higher tensile strength as increasing of CMF content. However as progressive increasing CMF content, the reverse result of $T_{g}$ value was occurred at 5\% CMF content. The decreasing of $T_{g}$ may results of hydrophilic nature of cellulose, thus an increasing of CMF causes of higher moisture in nanocomposite film at the same testing condition. Though the $T_{g}$ value of the zein nanocomposite film is decreased with increasing CMF content, the tensile strength is continually increased especially at $4 \mathrm{wt} \%$ of CMF. The web-like structure of CMF was the main effect on the increasing tensile strength of the nanocomposite film.

\section{Conclusion}

Zein/CMF nanocomposite films were developed from colloidal suspension of CMF and zein solution. The CMF, prepared by acid hydrolysis of cellulose from banana peel, consisted of interconnected web-like structure with an average diameter around $26 \mathrm{~nm}$. After the aqueous suspensions of CMF and zein solution were mixed and stirred, solid composite films were obtained by casting and evaporating methods. It was found that an incorporation of CMF was changed the surface morphology and improved tensile properties of the films. Especially, an increasing CMF content was resulted in increasing tensile strength and Young's modulus but decreasing in elongation at break of the zein nanocomposite films. By considering the easy of processing and the mechanical properties, the amount of cellulose microfibrils in zein film should not exceed 4 percent.

\section{Acknowledgements}

The support of Department of Tool and Materials Engineering, Faculty of Engineering, King Mongkut's University of Technology Thonburi is gratefully appreciated and acknowledged for the financial support of this re- search.

\section{REFERENCES}

[1] Y. Li, Y.-W. Mai and L. Ye, "Sisal Fibre and Its Composites: A Review of Recent Developments," Composites Science and Technology, Vol. 60, No. 11, 2000, pp. 2037-2055. doi:10.1016/S0266-3538(00)00101-9

[2] J. Prachayawarakorn, P. Sangnitidej and P. Boonpasith, "Properties of Thermoplastic Rice Starch Composites Reinforced by Cotton Fiber or Low-Density Polyethylene," Carbohydrate Polymers, Vol. 81, No. 2, 2010, pp. 425-433. doi:10.1016/j.carbpol.2010.02.041

[3] H. Ismail, S. Shuhelmy and M. R. Edyham, "The Effects of a Silane Coupling Agent on Curing Characteristics and Mechanical Properties of Bamboo Fibre Filled Natural Rubber Composites," European Polymer Journal, Vol. 38, No. 1, 2002, pp. 39-47. doi:10.1016/S0014-3057(01)00113-6

[4] N. Soykeabkaew, P. Supaphol and R. Rujiravanit, "Preparation and Characterization of Jute- and Flax-Reinforced Starch-Based Composite Foams," Carbohydrate Polymers, Vol. 58, No. 1, 2004, pp. 53-63. doi:10.1016/j.carbpol.2004.06.037

[5] T. Nishino, K. Hirao, M. Kotera, K. Nakamae and H. Inagaki, "Kenaf Reinforced Biodegradable Composite," Composites Science and Technology, Vol. 63, No. 9, 2003, pp. 1281-1286.

doi:10.1016/S0266-3538(03)00099-X

[6] M. Phiriyawirut, P. Saenpong, S. Chalermboon, R. Sooksakoolrut, N. Pochanajit, L. Vuttikit, A. Thongchai and P. Supaphol, "Isotactic Poly(Propylene)/Wood Sawdust Composite: Effects of Natural Weathering, Water Immersion, and Gamma-Ray Irradiation on Mechanical Properties," Macromolecular Symposia, Vol. 264, No. 1, 2008, pp. 59-66. doi:10.1002/masy.200850410

[7] M. A. S. Azizi Samir, F. Alloin and A. Dufresne, "Review of Recent Research into Cellulosic Whiskers, Their Properties and Their Application in Nanocomposite Field," Biomacromolecules, Vol. 6, No. 2, 2005, pp. 612-626. doi: $10.1021 / \mathrm{bm} 0493685$

[8] A. Turbak, F. Snyder and K. Sandberg, "Suspensions Containing Microfibrillated Cellulose," US Patent No. 4378381, 1983.

[9] E. Dinand, H. Chanzy and M. R. Vignon, "Suspension of Cellulose Microfibrils from Sugar Beet Pulp," Food Hydrocolloids, Vol. 13, No. 3, 1999, pp. 275-283. doi:10.1016/S0268-005X(98)00084-8

[10] A. Dufresne and M. Vignon, "Improvement of Starch Film Performances Using Cellulose Microfibrils," Macromolecules, Vol. 31, No. 8, 1998, pp. 2693-2696. doi:10.1021/ma971532b

[11] T. Imai, J. L. Putaux and J. Sugiyama, "Geometric Phase Analysis of Lattice Images from Algal Cellulose Microfibrils," Polymer, Vol. 44, No. 6, 2003, pp. 1871-1879. doi:10.1016/S0032-3861(02)00861-3

[12] M. E. Melainine, A. Dufresne, D. Dupeyre, M. Mahrouz, R. Vuong and M. Vignon, "Structure and Morphology of 
Cladobes and Spines of Opuntia Ficus-Indica. Cellulose Extraction and Characterization," Carbohydrate Polymers, Vol. 51, No. 1, 2003, pp. 77-83. doi:10.1016/S0144-8617(02)00157-1

[13] R. Zuluaga, J. L. Putaux, A. Restrepo, I. Mondragon and P. Ganan, "Cellulose Microfibrils from Banana Farming Residues: Isolation and Characterization," Cellulose, Vol. 14, No. 6, 2007, pp. 585-592. doi:10.1007/s10570-007-9118-Z

[14] M. Phiriyawirut, N. Chotirat, S. Phromsiri and I. Lohapaisarn, "Preparation and Properties of Natural RubberCellulose Microfibril Nanocomposite Films," Advanced Materials Research, Vol. 93-94, 2010, pp. 328-331. doi:10.4028/www.scientific.net/AMR.93-94.328

[15] M. Neus Anglès and A. Dufresne, "Plasticized Starch/ Tunicin Whiskers Nanocomposites: 1. Structural Analysis," Macromolecules, Vol. 33, No. 22, 2000, pp. 8344-8353. doi: $10.1021 / \mathrm{ma} 0008701$

[16] J. Sriupayo, P. Supaphol, J. Blackwell and R. Rujiravanit, "Preparation and Characterization of $\alpha$-Chitin WhiskerReinforced Chitosan Nanocomposite Films with or without Heat Treatment," Carbohydrate Polymer, Vol. 62, No. 2, 2005, pp. 130-136. doi:10.1016/j.carbpol.2005.07.013

[17] L. Chazeau, J. Y. Cavaille, G. Canova, R. Dendievel and B. Boutherin, "Viscoelastic Properties of Plasticized PVC Reinforced with Cellulose Whiskers," Journal of Applied Polymer Science, Vol. 71, No. 11, 1999, pp. 1797-1808. doi:10.1002/(SICI)1097-4628(19990314)71:11<1797::AI D-APP9>3.0.CO;2-E

[18] J. K. Sears and J. R. Darby, "Mechanism of Plasticizer Action," In: J. K. Sears and J. R. Darby, Eds., The Technology of Plasticizers, Wiley-Interscience, New York, 1982, pp. 35-77.

[19] R. Paramawati, T. Yoshino and S. Isobe, "Effect of Degradable Plasticizer on Tensile and Barrier Properties of Single Plasticized-Zein Film," Journal of Engineering Pertanian, Vol. 1, No. 1, 2003, pp. 49-57.

[20] D. Gioia, L. Guilbert and S. Guilbert, "Corn Protein-
Based Thermoplastic Resins: Effect of Some Polar and Amphiphilic Plasticizers," Journal of Agricultural and Food Chemistry, Vol. 47, No. 3, 1999, pp. 1254-1261. doi:10.1021/jf980976j

[21] E. L. Hult, T. Iversen and J. Sugiyama, "Characterization of the Supermolecular Structure of Cellulose in Wood Pulp Fibres," Cellulose, Vol. 10, No. 2, 2003, pp. 103-110. doi:10.1023/A:1024080700873

[22] J. Lu, T. Wang and L. T. Drzal, "Preparation and Properties of Microfibrillated Cellulose Polyvinyl Alcohol Composite Materials," Composites: Part A, Vol. 39, No. 5, 2008, pp. 768-746. doi:10.1016/j.compositesa.2008.02.003

[23] N. Parris and D. R. Coffin, "Composition Factors Affecting the Water Vapor Permeability and Tensile Properties of Hydrophilic Zein Films," Journal of Agricultural and Food Chemistry, Vol. 45, No. 5, 1997, pp. 1596-1599. doi:10.1021/jf960809o

[24] J. X. Sun, X. F. Sun, H. Zhao, R. C. Sun, "Isolation and Characterization of Cellulose from Sugarcane Bagasse," Polymer Degradation and Stability, Vol. 84, No. 2, 2004, pp. 331-339. doi:10.1016/j.polymdegradstab.2004.02.008

[25] F. X. Santosa and G. W. Padua, "Thermal Behavior of Zein Sheet Plasticized with Oleic Acid," Cereal Chemistry, Vol. 77, No. 4, 2000, pp. 459-462. doi:10.1094/CCHEM.2000.77.4.459

[26] B. Ghanbarzadeh, A. R. Oromiehie, M. Musavi, Z. E. D. Jomeh, E. R. Rad and J. Milani, "Effect of Plasticizing Sugars on Rheological and Thermal Properties of Zein Resins and Mechanical Properties of Zein Films," Food Research International, Vol. 39, No. 8, 2006, pp. 882-890. doi:10.1016/j.foodres.2006.05.011

[27] J. Magoshi, S. Nakamura and K. I. Murakamiki, "Structure and Physical Properties of Seed Proteins, Glass Transition and Crystallization of Zein Protein from Corn," Journal of Applied Polymer Science, Vol. 45, No. 11, 1992, pp. 2043-2048. doi:10.1002/app.1992.070451119 